Relations industrielles

Industrial Relations

\title{
Personnel Journal
}

\section{Gaston Cholette}

Volume 5, numéro 2, novembre 1949

URI : https://id.erudit.org/iderudit/1023282ar

DOI : https://doi.org/10.7202/1023282ar

Aller au sommaire du numéro

\section{Éditeur(s)}

Département des relations industrielles de l'Université Laval

ISSN

0034-379X (imprimé)

1703-8138 (numérique)

Découvrir la revue

Citer cet article

Cholette, G. (1949). Personnel Journal. Relations industrielles / Industrial Relations, 5(2), 19-19. https://doi.org/10.7202/1023282ar

Tous droits réservés (C Département des relations industrielles de l’Université Laval, 1949
Ce document est protégé par la loi sur le droit d'auteur. L’utilisation des services d'Érudit (y compris la reproduction) est assujettie à sa politique d'utilisation que vous pouvez consulter en ligne.

https://apropos.erudit.org/fr/usagers/politique-dutilisation/ 
LES REVUES EN RELATIONS INDUSTRIELLES

\section{REVUES GOUVERNEMENTALES}

Les revues gouvernementales en relations du travail occupent une place de choix. Les renseignements et les statistiques inédits d'ordre national et de caractère officiel que seules des publications de ce genre sont en mesure de fournir sont dimportance primordiale. Le Bulletin des relations industrielles s'empresse donc de présenter $d$ ses lecteurs les principales revues qui tombent dans cette catégorie.

Etant donné qu'elles ont en commun plusieurs caractéristiques, on a cru opportun de grouper ici celles des pays suivants: Canada, Etats-Unis, France et Belgique, en y joignant la Revue internationale du travail, publiée par le Bureau international du travail. Voici les titres des revues de ces pays dans l'ordre d'énumération de la phrase précédente: La Gazette du travail, Monthly Labor Review, Revue française du travail, Revue du travail.

LA GAZETTE DU TRAVAIL est un périodique mensuel de 100 à 150 pages publié par le Ministère fédéral du travail. Il compte actuellement cinquante années d'existence. Voici une liste de ses rubriques: «Le mois ouvrier en résumé », « Notes sur questions d'actualité », «Organisation internationale du travail \$, « Relations industrielles et conciliation $\gg$, Conventions collectives et régimes de salaires $\gg$, « Justes salaires dans les entreprises de l'Etat », «Législation ouvrière », «Assurance-chômage », « Situation courante de l'emploi », « Prix du coût de la vie », «Grèves et lock-out », \& La statistique ouvrière ». Il est bon de signaler que les statistiques fournies dans cette publication comportent un haut degré d'exactitude et d'actualité car le Bureau fédéral de la statistique est l'une des institutions de ce genre les mieux organisées au monde. Prix de l'abonnement: \$1.00. Adresse: Ministère du travail, Ottawa.

MONTHLY LABOR REVIEW est un périodique mensuel de 100 à 150 pages publié par le Bureau of Labor Statistics, United States Department of Labor. Il contient régulièrement trois ou quatre articles spéciaux, des chroniques sur une dizaine de sujets différents sous la rubrique « Summaries of Studies and Reports 》, des notes techniques portant habituellement sur des problèmes de statistique, enfin une section intitulée c Departments s, dans laquelle on trouve régulièrement cinq rubriques sur les matières suivantes: le mois ouvrier en résumé, décisions judiciaires d'intérêt ouvrier, chronique des récents événements ouvriers, publications en relations du travail, statistiques ouvrières. Prix de l'abonnement: \$5.75. Adresse: Superintendent of Documents, U.S. Government Printing Office, Washington 25, D.C.

La REVUE FRANÇAISE DU TRAVAIL est une publication mensuelle d'environ 150 pages éditée par le Ministère du travail et de la sécurité sociale de France. Elle contient ordinairement deux ou trois articles de fond et les rubriques suivantes: «L'activité sociale en France \$, 《L'activité sociale à l'étranger 》, \& Statistiques \$. Prix de l'abonnement: 1,650 francs. Adresse: Presses universitaires de France, 108, boulevard Saint-Germain, Paris VIe.
La REVUE DU TRAVAIL, publication mensuelle d'environ 200 pages, est l'organe du Ministère du travail et de la prévoyance sociale de Belgique. Voici la liste de ses principales rubriques: « Les conditions du travail s, « L'emploi et le chômage », « La sécurité sociale », 《L'activité sociale », « L'activité sociale internationale », «Chronique des travaux parlementaires $\gg$, \& Actes et documents officiels 》, « Jurisprudence 》, «Statistiques économiques et démographiques », « Bibliographie ». Prix de l'abonnement: 450 francs. Adresse: 2, rue Lambermont, Bruxelles.

La REVUE INTERNATIONALE DU TRAVAIL, périodique mensuel de 100 à 150 pages, est l'organe du Bureau international du travail. Elle contient des articles de fond, qui, rédigés par les services du Bureau ou des collaborateurs extérieurs, traitent de l'évolution de la politique sociale dans les différents pays et sur le plan international; des exposés documentaires groupés sous la rubrique « Rapports et enquêtes »: analyses de rapports officiels offrant un intérêt général, résultats de recherches entreprises par le Bureau; des statistiques du coût de la vie, du chômage, de l'emploi, des salaires et des heures de travail, que le Bureau est le seul à publier sous une forme aussi complète et systématique; enfin, une bibliographie de caractère international. Prix de l'abonnement: \$5.00. Adresse: Bureau international du travail, Genève, Suisse.

G. C.

\section{PERSONNEL JOURNAL}

« Personnel Journal 》 prétend être, dans l'ordre chronologique, la première des revues consacrées aux problèmes du personnel et aux relations industrielles. Elle date de 1922.

C'est une publication mensuelle d'environ quarante pages contenant régulièrement cinq ou six articles, une couple de petits éditoriaux, une section réservée aux lettres des lecteurs, une chronique de livres et de revues, etc.

Elle est préparée à Swarthmore, Pennsylvanie, sous la direction de Edward N. Hay. La plupart des collaborateurs sont des personnes qui travaillent à des postes de commande au service d'entreprises de grande importance; plusieurs articles, d'autre part, son rédigés par des universitaires. Elle comporte ainsi l'avantage de présenter des études qui sont le fruit d'expériences pratiques et de recherches scientifiques.

- Personel Journal , fournit surtout des travaux qui exposent des faits, qui présentent des expériences. On n'y trouve pas souvent d'articles de réllexion philosophique sur l'entreprise et les relations du travail.

La plupart des articles qui y sont publiés portent sur l'administration du personnel, notamment sur l'évaluation des tâches. Une étude très bien faite à ce sujet a paru dans le numéro d'avril 1949, sous le titre: «anagement Fositions Can Be Evaluated Successfully ». On y raconte une expérience vraiment remarquable réalisée par un grand établissement, pendant une période de trois ans, dans le but de fixer le plus scientifiquement possible les échelles de salaires de ses employés supérieurs, en tenant compte du degré de connaissances, d'esprit de décision et de responsabilités requis dans l'exécution de chaque tâche.

On s'abonne à cette revue, au prix de $\$ 6.00$ par annee, en s'adressant d "Personnel Journal", Swarthmore, Pa., U.S.A.

G. C. 